\title{
Preparation for colonoscopy: types of scales and cleaning products
}

\author{
Vicente Lorenzo-Zúñiga ${ }^{1,2}$, Vicente Moreno-de-Vega ${ }^{1}$ and Jaume Boix ${ }^{1}$ \\ ${ }^{\prime}$ Endoscopy Unit. Department of Gastroenterology. Hospital Universitari Germans Trias i Pujol. Badalona, Barcelona. \\ Spain. ${ }^{2}$ Centro de Investigación Biomédica en Red de Enfermedades Hepáticas y Digestivas (CIBERehd). Spain
}

\begin{abstract}
Adequate bowel preparation is essential before a colonoscopy, allowing us to make a proper examination of the entire mucosa. The ideal method of colon cleansing should be fast, safe, and get a proper cleaning with minimal discomfort for the patient. Today we have a wide variety of colon cleansing products, information sometimes becomes confused. A good colon preparation depends partly on correct choice of the same, but also upon dietary restriction. Knowledge of all these products, with their advantages and limitations, we can make a better selection for each patient, and although the efficacy is comparable, is the experience of the browser, patient preferences, and the degree of compliance with the instructions preparation, which greatly influence the results.
\end{abstract}

Key words: Colonoscopy. Colon preparation. Types of scales. Cleaning products.

Lorenzo-Zúñiga V, Moreno de Vega V y Boix J. Preparación para colonoscopia: tipos de productos y escalas de limpieza. Rev Esp Enferm Dig 2012; 104:426-431.

Received: 29-02-2012

Accepted: 22-06-2012

Correspondence: Vicente Lorenzo-Zúñiga García. Endoscopy Unit. Department of Gastroenterology/CIBERehd. Hospital Universitari Germans Trias i Pujol. Carretera del Canyet, s/n. 08916 Badalona, Barcelona. Spain e-mail: vlorenzo.germanstrias@gencat.cat

\section{INTRODUCTION}

Colonoscopy is the primary method for evaluating the colon, but effective diagnostic and treatment depends on the quality of the technique. The defining characteristics of high-quality colonoscopy is the examination of the entire colon, optimal cleaning of the colon and endoscope withdrawal time of 6-10 min from cecum to rectum (1-3). In this regard, insufficient preparation reduces the quality of the procedure, increases the risk of complications, decreases the rate of detection of adenomas, extends the exploration and induces a new application for endoscopy in a shorter time than recommended in the guidelines clinical practice (4).

\section{METHODS FOR CLEANING}

The ideal method of colon cleansing should be fast, safe, and get a proper cleaning with minimal discomfort for the patient $(5,6)$. It should be easy to perform to allow carrying out both inpatient and outpatient (7).

Adequate colon preparation depends partly on a correct choice of cleaning product, but also upon dietary restriction (8). Knowledge of all these products, with their advantages and limitations, permits a better selection for each patient $(9,10)$. Although its efficacy is comparable, the browser experience, patient preferences, and the degree of compliance with the directions, greatly influence the results. Therefore, we must be very careful with the explanations given to patients and should be advised to maintain proper hydration. Also, they should provide a permanent telephone number where the patient can solve all questions that are asked (11).

Currently we have several options for preparing patients for colonoscopy. Products for colon cleansing can be classified into two groups: Osmotic agents and stimulants $(12,13)$. 


\section{Osmotic agents}

These products exert their action by increasing water retention in the colon or to stimulate its secretion $(5,14)$. Of these, the solutions based on polyethylene glycol (PEG) are the most used. They are metabolically inert substances no absorbable (PEG) or hyperosmolar salt (sodium phosphate, magnesium citrate, lactulose, and mannitol).

\section{PEG-based solutions}

In 1980, Davis and colleagues developed a solution for cleaning the intestines not carries with it the absorption or secretion of water and salts (15). This isosmotic solution was composed of $125 \mathrm{mmol} / \mathrm{L}$ sodium, $40 \mathrm{mmol} / \mathrm{L} \mathrm{SO}_{4}, 35$ $\mathrm{mmol} / \mathrm{L}$ of chlorine, $20 \mathrm{mmol} / \mathrm{L}$ bicarbonate, $10 \mathrm{mmol} / \mathrm{L}$ potassium and PEG, a no absorbable polymer with high molecular weight. Sodium is absorbed in the digestive tract actively when accompanied by the chlorine anion. But the active absorption is reduced when sodium sulphate is substituted by chlorine and sulphate itself is not absorbed. Sodium gradient occurs very little: a small passive sodium secretion is counteracted by an active absorption of the same, so that the net movement of sodium is almost nil. The movement of potassium in the gastrointestinal tract is passive in response to chemical and electrical gradient. cleansing with PEG solution intake need 3- in a three or four hours, with a minimum exchange of fluids and electrolytes (7).

These solutions are better tolerated and more effective and safer than other osmotic agents (16). The main disadvantage of these products is the large amount of volume () that patients should ingest and taste salty because sodium sulphate. Typically recommended intake of $250 \mathrm{ml}$ every 15 minutes to complete the or until clear fluid is expelled. They are available with the following trade names:

- Solución evacuante Bohm ${ }^{\circledast}$, Casenglicol ${ }^{\circledR}$. With these solutions 85 to $95 \%$ of patients achieve a good cleaning of the colon (17). It is a safe cleaning method in patients with electrolyte problems (kidney failure, heart failure, or liver failure with ascites), being the method of choice in children. The main side effects (nausea, bloating, and vomiting) are secondary to the volume ingested. They are very safe and inexpensive, but $5-15 \%$ of patients do not complete the preparation for its salty taste and/or volume (17). To improve tolerability flavoured solutions have been developed (without sulphate) and other low volume (4 liters) $(18,19)$. PEG solutions, which have been removed sulphate in an attempt to improve its taste salty, are available with different flavours (cherry, lemon, orange and pineapple), but are not marketed in our country.

- Moviprep® is a hypertonic solution resulting from the combination of PEG and ascorbic acid, which has been developed to improve tolerance and acceptance of conventional solutions of , achieving the same efficiency with a smaller volume ( 2 liters). Ascorbic acid acts as a flavouring and exerts a synergistic osmotic action to PEG, thereby enabling it is needed a smaller volume of solution. In this regard, studies have shown that smaller volume preparations are more effective and better tolerated by patients (20).

\section{Osmotic solutions hyperosmolar}

Osmotic laxatives are mainly based on sodium phosphate (Fosfosoda Fleet ${ }^{\circledR}$ ). In the 90 's began to use the sodium phosphate solution $(21,22)$. Sodium phosphate is a saline laxative, which has the advantage of small volume required ( 2 vials of $45 \mathrm{~mL}$ ) to achieve a proper colon cleansing, be as effective as and better tolerated by patients than PEG solution (23). As with the other methods used to prepare the colon, sodium phosphate is not without side effects, can cause electrolyte problems (hyperphosphatemia, hypocalcaemia, hypokalemia, plasma hyperosmolality, hyponatremia and hypernatremia) $(5,24)$. Therefore, in patients with impaired renal function, dehydration, hypercalcemia, or hypertension requiring drug inhibitors of angiotensin converting enzyme (ACE) inhibitors, their use is discouraged, since they have experienced phosphate nephropathy, related with age and the dose of the drug (25). Moreover aphthoid lesions have been described in the colon after administration, so its usefulness is diminished in patients with inflammatory bowel disease.

Other options include the use of magnesium citrate, which is not marketed in as monotherapy, although not recommended for use in patients with impaired renal function (26).

\section{Stimulating agents}

Cathartics products or stimulants produce a contraction of the colonic wall that stimulates the evacuation thereof. Today we have a combination of sodium picosulfate magnesium oxide and citric acid (CitraFleet $\left.{ }^{\circledast}\right)(26,27)$ and bisacodyl (Dulcolaxo $\left.{ }^{\circledast}\right)$ $(28,29)$. Its effectiveness lies in $70-80 \%$ of patients, but may be associated with electrolyte problems and dehydration.

Sodium picosulfate acts locally as a stimulating agent after biotransformation by colonic bacteria in an active compound, while the magnesium oxide as osmotic laxative does, retaining fluid in the colon. Since exclusively the kidney eliminates magnesium, it must take special care of patients with renal insufficiency. The preparation with $\mathrm{CitraFleet}^{\circledR}$ is accomplished by administering two envelopes dissolved in $250 \mathrm{~mL}$ of water each, together with a subsequent water intake not less than 2 litres.

Bisacodyl presents a therapeutic action as a laxative, which increases intestinal motility by stimulating the nerve endings in the intestinal wall. Inhibits absorption and increases secretion of water and electrolytes, which reduces the consistency and increases fecal volume. The appropriate dose of bisacodyl may be different for each patient, but usually given 5 to $10 \mathrm{mg}$ ( 1 or 2 tablets) administered 


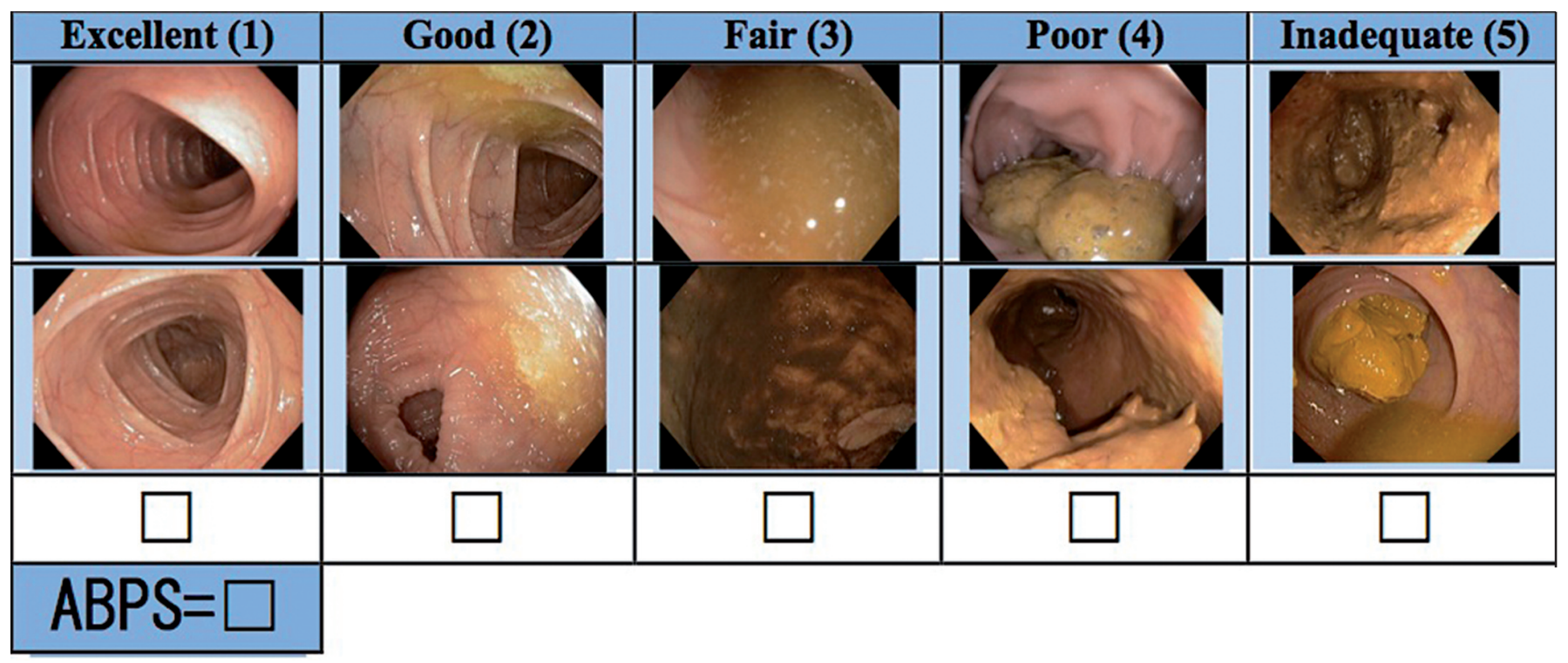

Fig. 1. Aronchick bowel preparation scale (ABPS).

preferably before bedtime. Bisacodyl regimens usually require administration of at least 2 days, and combine them with enemas and dietary restrictions.

\section{EVALUATION OF PREPARATION: CLEANING SCALES}

In all colonoscopies should comprise the preparation quality of the colon. The quality criterion is to achieve a preparation good or very good in $95 \%$ of scans (1-3). The preparation of the colon must be notified in the endoscopy report using validated assessment scales. Poor preparation is the biggest impediment to an adequate examination, reducing the ability to detect polyps, lengthens the procedure time and worsens the cost-effectiveness to induce a decrease in the interval between scans (2). Preparation is considered good or very good one in which you have the impression of having been observed, with acceptable accuracy, the existence of polyps equal or greater size of $5 \mathrm{~mm}$.

To date, have proposed various validated assessment scales: Aronchick (30), Ottawa (31) and Boston (32).

\section{Aronchick Bowel Preparation Scale (ABPS)}

The ABPS is the oldest of the three, and perhaps the simplest, albeit with a large interobserver variability. Is a scoring scale of 1 to 5 points on the entire colon (30) (Fig. 1).

- Excellent (1 point): Small volume of clear liquid or greater than $95 \%$ of surface seen.

- Good (2 points): Large volume of clear liquid covering 5 to $25 \%$ of the surface but greater than $90 \%$ of surface seen.
- Fair (3 points): Some semisolid stool that could be suctioned or washed away but greater than $90 \%$ of surface seen.

- Poor (4 points): Semisolid stool that could not be suctioned or washed away and less than $90 \%$ of surface seen.

- Inadequate (5 points): Solid stool that impede the vision. Repeat preparation and colonoscopy is needed.

\section{Ottawa Bowel Preparation Scale (OBPS)}

The OBPS was developed and validated in order to allow evaluation of the colon segments. Is a scale score of 0 to 14 points, published in Gastrointestinal Endoscopy in 2004 (31). In its construction takes into account two aspects summations: degree of cleaning segment of the colon (left colon, transverse colon and right colon) and amount of fluid in the entire colon (Fig. 2).

Score of 0 to 4 points per segment:

- Excellent (0 points): Mucosa clearly visible. Minimum liquid remains.

- Good (1 point): Some liquid remains. Good view of the mucosa.

- Fair (2 points): Blow liquid or semisolid. No precise wash. Reasonable view of the mucosa.

- Poor (3 points): Blow sucks needing wash. Low vision of the mucosa.

- Inadequate (4 points): Blow solids that impede vision.

Amount of liquid in the entire colon, from 0 to 2 points:

- Low (0 points).

- Moderate (1 point).

- Large (2 points). 


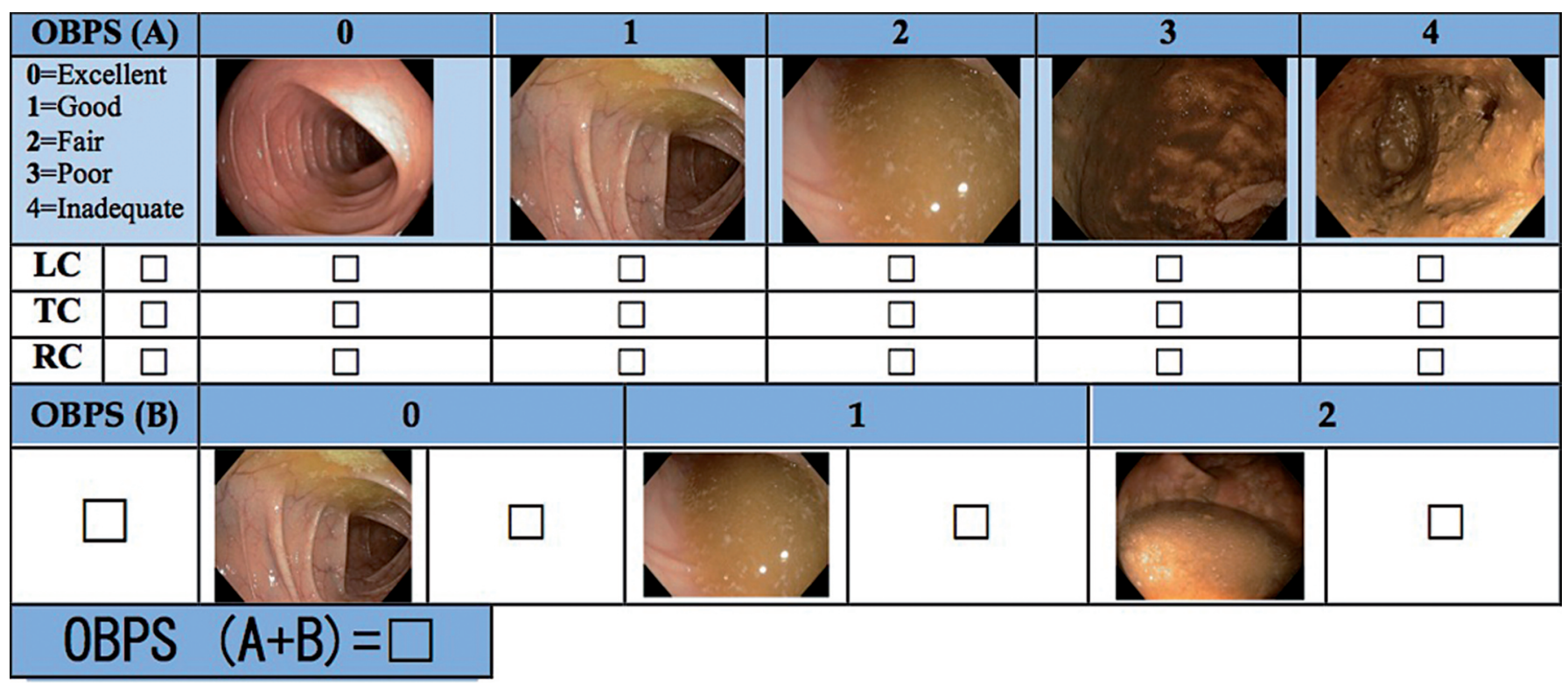

Fig. 2. Ottawa bowel preparation scale (OBPS). LC: Left colon. TC: Transverse colon. RC: Right colon.

\section{Boston Bowel Preparation Scale (BBPS)}

The BBPS was developed by the section of gastroenterology at Boston Medical Center (BMC) to provide a muchneeded standard for rating the quality of bowel preparation for colonoscopy. This tool, published in October 2010 in the journal Gastrointestinal Endoscopy (32) shows the level of accuracy and could become a standard tool for cleaning international index colon during colonoscopy (33) (Fig. 3).

Three segments of the colon (left, transverse, right) are ranked based on your cleaning

- 0 points: Segment unprepared colon with mucosa not visualized by the presence of solid stool.

- 1 point: Areas colon segment seen by the presence of fecal liquid and semisolid.

- 2 points: Low fecal fluid content allows good visualization of the mucosa.

- 3 points: Excellent visualization of the mucosa without the presence of liquid remains.

\section{CLEANING MEASURES TO IMPROVE THE COLON}

The inappropriate percentage that has been reflected in several clinical studies, is around $21 \%$ (34).

\section{Divide the daily dose of PEG solution (splits-dose regimen)}

A measure to improve tolerability and adherence to PEGbased solutions is to divide the dose (split-dose regimen).
Thus, patients take a half dose the night before and half in the $4-5$ hours before the scan $(35,36)$.

\section{Time management}

The time of administration of the product is crucial. The protocols must indicate the benefit of that preparation starts between 8 and 12 hours before scanning and close between 4 and 6 hours before to get the best colon cleansing, while it is feasible seudoanalgesia management with minimal risk (37). A range of 5 to 8 hours between the last dose and colonoscopy provides the best cleaning quality, while a range exceeding 14 hours has poor preparation of the colon (38).

\section{Dietary restriction}

A low-residue diet in the days before the scan (1-5 days) reduces the amount of feces, albeit insufficient by itself to get a proper cleaning of the colon (8).

\section{Cleansing enemas}

Enemas act by dilution or irritation, and rarely get effective cleaning alone. His administration is uncomfortable for patients, but is helpful in those patients presenting in the endoscopy unit with inadequate cleaning (39).

\section{REFERENCES}

1. Gonzalez-Huix Llado F, Figa Francesch M, Huertas Nadal C. Essential quality criteria in the indication and performance of colonoscopy. Gastroenterol Hepatol 2010;33:33-42. 


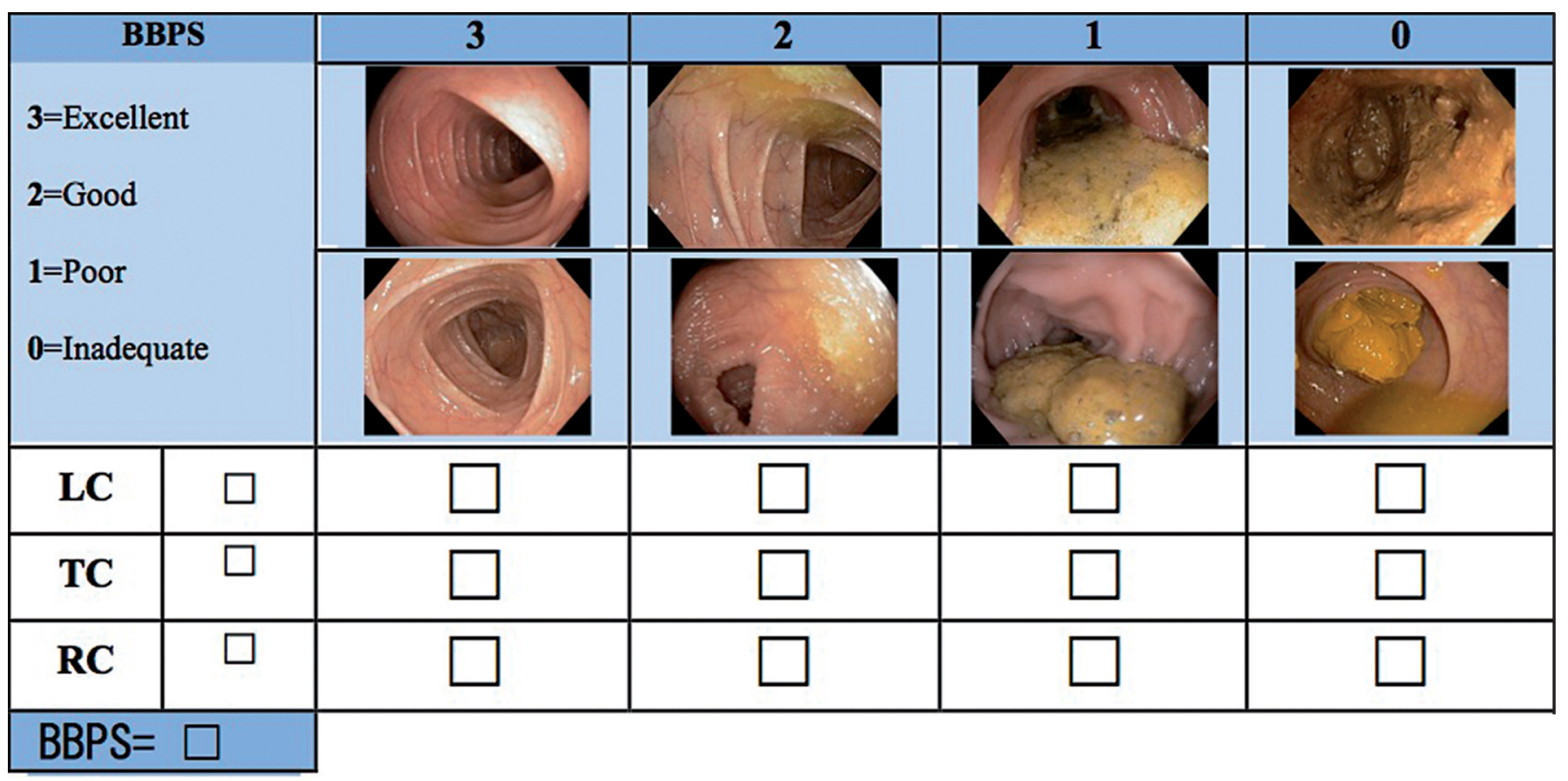

Fig. 3. Boston bowel preparation scale (BBPS). LC: Left colon. TC: Transverse colon. RC: Right colon.

2. Morán Sánchez S, Torrella E, Esteban Delgado P, Baños Madrid R, García A, Ono A, et al. Colonoscopy quality assessment. Rev Esp Enferm Dig 2009;101:107-12, 112-6.

3. Jover R, Herráiz M, Alarcón O, Brullet E, Bujanda L, Bustamante M, et al. Clinical practice Guidelines: quality of colonoscopy in colorectal cancer screening. Endoscopy 2012;44:444-51.

4. Froehlich F, Wietlisbach V, Gonvers JJ, Burnand B, Vader JP. Impact of colonic cleansing on quality and diagnostic yield of colonoscopy: The European panel of appropriateness of gastrointestinal endoscopy european multicenter study. Gastrointest Endosc 2005;61:378-84.

5. Kim HN, Raju GS. Bowel preparation and colonoscopy technique to detect non-polypoid colorectal neoplasms. Gastrointest Endosc Clin N Am 2010;20:437-48.

6. Atreja A, Nepal S, Lashner BA. Making the most of currently available bowel preparations for colonoscopy. Cleve Clin J Med 2010;77:317-26.

7. Beck DE. Bowel preparation for colonoscopy. Clin Colon Rectal Surg 2010;23:10-3

8. Wu KL, Rayner CK, Chuah SK, Chiu KW, Lu CC, Chiu YC. Impact of low-residue diet on bowel preparation for colonoscopy. Dis Colon Rectum 2011;54:107-12.

9. Landreneau SW, Di Palma JA. Update on preparation for colonoscopy. Curr Gastroenterol Rep 2010;12:366-73.

10. Ledo Barro L, Ulla Rocha JL. Bowel preparation for colonoscopy. Rev Esp Enferm Dig 2007;99:114.

11. Nguyen DL, Wieland M. Risk factors predictive of poor quality preparation during average risk colonoscopy screening: The importance of health literacy. J Gastrointestin Liver Dis 2010;19:369-72.

12. Lichtenstein G. Bowel preparations for colonoscopy: A review. Am J Health Syst Pharm 2009;66:27-37.

13. Occhipinti KE, Di Palma JA. How to choose the best preparation for colonoscopy. Nat Rev Gastroenterol Hepatol 2009;6:279-86.

14. Adamiak T, Altaf M, Jensen MK, Sultan M, Ramprasad J, Ciecierega $\mathrm{T}$, et al. One-day bowel preparation with polyethylene glycol 3350: An effective regimen for colonoscopy in children. Gastrointest Endosc 2010;71:573-7.

15. Davis GR, Santa Ana CA, Morawski SG, Fordtran JS. Development of a lavage solution associated with minimal water and electrolyte absorption or secretion. Gastroenterology 1980;78(5 Pt 1):991-5.
16. Nyberg C, Hendel J, Nielsen $\mathrm{OH}$. The safety of osmotically acting cathartics in colonic cleansing. Nat Rev Gastroenterol Hepatol 2010; 7:557-64.

17. Juluri R, Eckert G, Imperiale TF. Meta-analysis: Randomized controlled trials of 4-L polyethylene glycol and sodium phosphate solution as bowel preparation for colonoscopy. Aliment Pharmacol Ther 2010; $32: 171-81$

18. Haapamaki MM, Lindstrom M, Sandzen B. Low-volume bowel preparation is inferior to standard 41 polyethylene glycol. Surg Endosc 2011;25:897-901.

19. Corporaal S, Kleibeuker JH, Koornstra JJ. Low-volume PEG plus ascorbic acid versus high-volume PEG as bowel preparation for colonoscopy. Scand J Gastroenterol 2010;45:1380-6.

20. Ell C, Fischbach W, Bronisch HJ, Dertinger S, Layer P, Rünzi M, et al. Randomized trial of low-volume PEG solution versus standard PEG + electrolytes for bowel cleansing before colonoscopy. Am J Gastroenterol 2008;103:883-93.

21. Belsey J, Epstein O, Heresbach D. Systematic review: Adverse event reports for oral sodium phosphate and polyethylene glycol. Aliment Pharmacol Ther 2009;29:15-28.

22. Brunelli SM, Feldman HI, Latif SM, Gupta M, Weiner MG, Lewis JD. A comparison of sodium phosphosoda purgative to polyethylene glycol bowel preparations prior to colonoscopy. Fam Med 2009;41:39-45.

23. Schanz S, Kruis W, Mickisch O, Kuppers B, Berg P, Frick B, et al. Bowel preparation for colonoscopy with sodium phosphate solution versus polyethylene glycol-based lavage: A multicenter trial. Diagn Ther Endosc 2008;2008:713521.

24. Shawki S, Wexner SD. How safe is bowel preparation with oral sodium phosphate solution? Nat Clin Pract Gastroenterol Hepatol 2008; 5:482-3.

25. Yakut M, Cinar K, Seven G, Cetinkaya H, Bahar K. The efficacy and safety of colonoscopy preparation with oral sodium phosphate in elderly patients. Turk J Gastroenterol 2010;21:140-5.

26. Renaut AJ, Raniga S, Frizelle FA, Perry RE, Guilford L. A randomized controlled trial comparing the efficacy and acceptability of phosposoda buffered saline (Fleet) with sodium picosulphate/magnesium citrate (Picoprep) in the preparation of patients for colonoscopy. Colorectal Dis 2008;10:503-5. 
27. Choi YS, Suh JP, Kim JK, Lee IT, Youk EG, Lee DS, et al. Magnesium citrate with a single dose of sodium phosphate for colonoscopy bowel preparation. World J Gastroenterol 2011;17:242-8.

28. Enestvedt BK, Fennerty MB, Eisen GM. Randomised clinical trial: MiraLAX vs. golytely - a controlled study of efficacy and patient tolerability in bowel preparation for colonoscopy. Aliment Pharmacol Ther 2011;33:33-40.

29. Malik P, Balaban DH, Thompson WO, Galt DJ. Randomized study comparing two regimens of oral sodium phosphates solution versus low-dose polyethylene glycol and bisacodyl. Dig Dis Sci 2009;54: 833-41.

30. Aronchick CA. Bowel preparation scale. Gastrointest Endos. 2004; 60:1037,8; author reply 1038-9.

31. Rostom A, Jolicoeur E. Validation of a new scale for the assessment of bowel preparation quality. Gastrointest Endosc 2004;59:482-6.

32. Calderwood AH, Jacobson BC. Comprehensive validation of the Boston bowel preparation scale. Gastrointest Endosc 2010;72:686-92.

33. Lai EJ, Calderwood AH, Doros G, Fix OK, Jacobson BC. The Boston bowel preparation scale: A valid and reliable instrument for colonoscopy-oriented research. Gastrointest Endosc 2009;69(3 Pt 2):620-5.
34. Ness RM, Manam R, Hoen H, Chalasani N. Predictors of inadequate bowel preparation for colonoscopy. Am J Gastroenterol 2001;96: 1797-802.

35. Varughese S, Kumar AR, George A, Castro FJ. Morning-only onegallon polyethylene glycol improves bowel cleansing for afternoon colonoscopies: A randomized endoscopist-blinded prospective study. Am J Gastroenterol 2010;105: 2368-74.

36. Park SS, Sinn DH, Kim YH, Lim YJ, Sun Y, Lee JH, et al. Efficacy and tolerability of split-dose magnesium citrate: Low-volume (2 liters) polyethylene glycol vs. single- or split-dose polyethylene glycol bowel preparation for morning colonoscopy. Am J Gastroenterol 2010; 105:1319-26.

37. Eun CS, Han DS, Hyun YS, Bae JH, Park HS, Kim TY, et al. The timing of bowel preparation is more important than the timing of colonoscopy in determining the quality of bowel cleansing. Dig Dis Sci 2011:56:539-44.

38. Gurudu SR, Ratuapli S, Heigh R, DiBaise J, Leighton J, Crowell M. Quality of bowel cleansing for afternoon colonoscopy is influenced by time of administration. Am J Gastroenterol 2010;105:2318-22.

39. Ben-Horin S, Bar-Meir S, Avidan B. The outcome of a second preparation for colonoscopy after preparation failure in the first procedure. Gastrointest Endosc 2009;69(3 Pt 2):626-30. 